\title{
Ecophysiology of Acetoclastic Methanogens
}

\author{
Alfons J. M. Stams, Bas Teusink, and Diana Z. Sousa
}

\section{Contents}

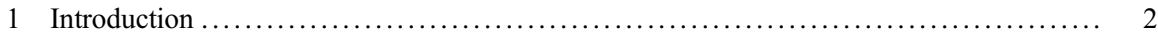

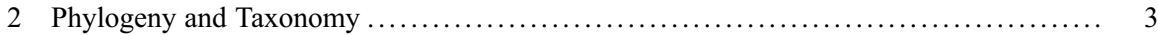

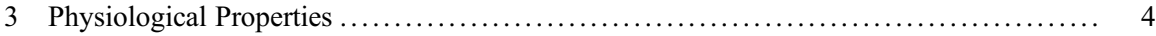

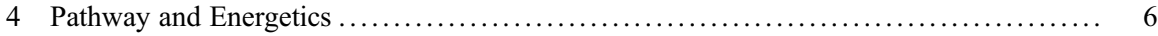

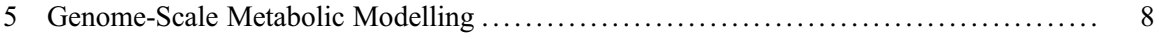

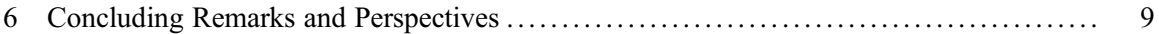

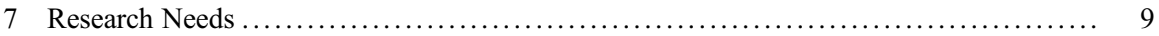

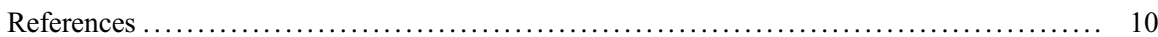

\begin{abstract}
Acetate is the most important precursor for methane in the degradation of organic matter. Only two genera of methanogenic archaea, Methanosarcina and Methanothrix (former Methanosaeta), are able to grow with acetate as sole energy and carbon source. Phylogenetically, Methanosarcina and Methanothrix both belong to the Methanosarcinales. These two genera show besides morphological differences, interesting differences in physiology. Methanosarcina is a generalist that can grow on a variety of substrates, while Methanothrix
\end{abstract}

\footnotetext{
A. J. M. Stams $(\bowtie)$

Laboratory of Microbiology, Wageningen University and Research, Wageningen, The Netherlands Centre of Biological Engineering, University of Minho, Braga, Portugal e-mail: fons.stams@wur.nl

B. Teusink

Laboratory of Systems Bioinformatics, Free University of Amsterdam, Amsterdam, The Netherlands e-mail: b.teusink@vu.nl

D. Z. Sousa

Laboratory of Microbiology, Wageningen University and Research, Wageningen, The Netherlands e-mail: diana.sousa@wur.nl
} 
specialized in growth on acetate. The acetate metabolism shows differences in acetate activation and energy conservation. At conditions that are less favorable for acetoclastic methanogens, syntrophic acetate oxidation may occur. This, however, is not further addressed here.

\section{Introduction}

In anaerobic environments where inorganic electron acceptors, such as nitrate, $\mathrm{Fe}(\mathrm{III}), \mathrm{Mn}(\mathrm{IV})$, or sulfate and sulfur, are limiting complex organic matter is decomposed to methane and carbon dioxide as main products (Stams and Plugge 2009). This involves a series of sequential conversions performed by communities of fermentative anaerobic bacteria and methanogenic archaea. Anaerobic bacteria degrade the organic compounds to products, typically hydrogen, carbon dioxide, formate, and acetate, which are the main substrates of methanogens. When organic matter is completely degraded, about $60-70 \%$ of the methane is formed from acetate, the remainder from $\mathrm{H}_{2}+\mathrm{CO}_{2}$ and formate. This shows the quantitative importance of acetate in the formation of the hydrocarbon methane.

The fate of acetate in a methanogenic environment is largely dependent on the chemo-physical conditions, such as temperature, $\mathrm{pH}$, salt, and presence of inhibitory compounds, e.g., ammonium. At circumneutral $\mathrm{pH}$ and at low or moderately high temperature, acetate is directly degraded by methanogenic archaea. Just two genera of acetotrophic methanogens, Methanothrix (former Methanosaeta) and Methanosarcina, are able to grow on acetate. Syntrophic acetate degradation can occur as well. This is particularly important at conditions where acetotrophic methanogens cannot grow well, which is typically the case in environments with a high ammonium concentration, high temperature (above $60^{\circ} \mathrm{C}$ ), and high salt/high $\mathrm{pH}$. The first observation of syntrophic acetate oxidation was done by Zinder and Koch (1984). They enriched a culture with acetate at $60^{\circ} \mathrm{C}$ and obtained a coculture of a bacterium and a hydrogenotrophic methanogen. Syntropic conversion was further demonstrated by using labeled substrates. Acetoclastic methanogens split acetate to methane and $\mathrm{CO}_{2}$, where the methyl-group yields methane and the carboxyl-group $\mathrm{CO}_{2}$. During syntrophic acetate oxidation, both C-atoms of acetate are first converted to $\mathrm{CO}_{2}$ and the methanogen uses the formed $\mathrm{CO}_{2}$ to produce methane. Consequently, during syntrophic acetate oxidation labeled methane is formed when unlabeled acetate and labeled $\mathrm{CO}_{2}$ are provided. This strategy was regularly applied to demonstrate syntrophic acetate oxidation in other environments, e.g., in environments with ammonium concentrations that are inhibitory for acetoclastic methanogens (Schnürer et al. 1999). 


\section{$2 \quad$ Phylogeny and Taxonomy}

The two known acetotrophic methanogenic genera are Methanothrix ("Methanosaeta") and Methanosarcina. These two genera belong to the order Methanosarcinales within the archaeal kingdom Euryarchaeota. Described mesophilic and thermophilic Methanosarcina species include, M. barkeri, M. mazei, M. acetivorans, M. baltica, M. frisia, M. horonobensis, M. lacustris, M. semesiae, $M$. siciliae, M. soligelidi, M. vacuolata, and M. thermophila. Methanothrix species include M. soehngenii, M. concilii, and M. harundinacea, which are mesophiles, and the thermophiles $M$. thermoacetophila and $M$. thermophila. The synonym for Methanothrix is Methanosaeta. Based on a long-standing discussion, the most recent opinion of the International Committee on Systematics of Prokaryotes (Tindall 2014), Methanothrix is appropriate and this name is used throughout this chapter, though Methanosaeta is most-often used in publications of the last decade.

In pioneering studies by Nicolaas L. Söhngen and later by Horace A. Barker, sarcina type methanogens were enriched (Söhngen 1906; Barker 1936). The first pure culture of Methanosarcina barkeri was obtained by Schnellen (1947), and since then many mesophilic and thermophilic Methanosarcina species have been isolated and described.

Methanothrix soehngenii was first described by Huser et al. (1982) and later Methanothrix concilli was described (Patel 1984). Based on a comparative analysis of Methanothrix strains, it was concluded that $M$. concilli is a synonym of $M$. soehngenii (Touzel et al. 1988). As the M. soehngenii culture was not pure, its name was found not be valid according to rule 31a of the International Code of Nomenclature of Bacteria stating that "the name of a species or subspecies is not validly published if the description is based upon studies of a mixed culture of more than one species or subspecies" and Methanosaeta concilli was proposed as the type strain of filamentous acetoclastic methanogens (Patel and Sprott 1990). Similarly, a thermophilic acetoclastic methanogen had been described, Methanothrix thermoacetophila (Nozhevnikova and Chudina 1985). However, as that name was never validated and the culture turned out not to be pure also that name was considered not to be valid, and Methanothrix thermophila was described by Kamagata et al. (1992) to represent thermophilic acetoclastic filamentous methanogens. That archaeon was proposed to be named Methanosaeta thermophila (Boone and Kamagata 1998), which was approved by the International Committee on Systematics of Prokaryotes (Tindall 2008). However, recently both Methanothrix soehngenii and Methanothrix thermoacetophila were reestablished as valid names based on a changed view of the interpretation of rule 31a, "the name of a species or a subspecies is not validly published if the description is demonstrably ambiguous and cannot be critically identified for purposes of the precise application of the name of a taxon" (Tindall 2014). 


\section{$3 \quad$ Physiological Properties}

Methanosarcina and Methanothrix are morphologically and physiologically different. Morphologically, the sarcina-shape and thix-shape are represented in the genus names. The cell wall structure of the two types of methanogens is also different. As most methanogens, Methanosarcina and Methanothrix contain S-layers which are mostly composed of a single protein or glycoprotein which is associated with the cytoplasmic membrane (Albers and Meyer 2011). The cell wall of Methanosarcina contains methanochondroitin, which is a fibrillar polymer composed of a trimer repeat of two $\mathrm{N}$-acetylgalactosamines and one glucuronic acid. Its formation is associated with the aggregated form of Methanosarcina (Kreisl and Kandler 1986). Methanothrix concilii has a rather complex cell envelope. The filamentous chains are enclosed by a unique tubular paracrystalline proteinaceous sheath surrounding the S-layer and the cytoplasmic membranes.

Physiologically, Methanosarcina and Methanothrix show interesting differences. Methanosarcina has a broader substrate range. Besides acetate, Methanosarcina species can grow with $\mathrm{H}_{2}+\mathrm{CO}_{2}$, methanol and methylated amines. It can be considered as a generalist. Methanothrix is a specialist that only uses acetate as growth substrate, though as discussed later it also has the ability to convert $\mathrm{CO}_{2}$ to methane, without the involvement of hydrogenases. The growth behavior of the two types of methanogens is different. While Methanosarcina shows faster growth, Methanothrix has a higher affinity for acetate (Table 1). The higher affinity has been associated with the enzyme systems for acetate activation (Jetten et al. 1990). The difference in acetate transport was proposed to play a role as well (Smith and Ingram-Smith 2011). The differences in specific growth rate and affinity for acetate make Methanosarcina easily enriched using routine isolation procedures, while Methanothrix is often the most abundant acetoclastic methanogens in environments where a low acetate concentration is observed.

Methanosarcina is considered to be a rather robust methanogen in comparison with Methanothrix as it grows faster with acetate and can use other substrates. In addition, Methanosarcina can better resist and recover when exposed to stressors such as ammonium, chlorinated compounds, salt, and high acetate concentration (De Vrieze et al. 2012). In comparison with Methanothrix, Methanosarcina is most resistant to oxygen. Recently, even the cocultivation with aerobic methanotrophs was described (in 't Zandt et al. 2018). However, there are examples where Methanothrix seems to be more resistant. Methanothrix is more resistant to longchain fatty acids (Silva et al. 2016) and humic substances (Azman et al. 2017) than Methanosarcina. The higher tolerance in these cases was thought to be related to the different cell wall structure.

In recent years, there is quite some attention for direct electron transfer in methanogenic microbial communities, with or without electron mediators (Lovley 2017; Martins et al. 2018). Acetoclastic methanogens have been described to accept directly electrons provided by another bacterium or a solid surface to produce methane from $\mathrm{CO}_{2}$. Morita et al. (2011) suggested the potential of direct interspecies electron transfer in a methanogenic bioreactor. In an ethanol-fed bioreactor, 
Table 1 Comparison of the physiological parameters of Methanosarcina spp. and Methanothrix spp. (Jetten et al. 1990)

\begin{tabular}{l|l|l}
\hline & Methanosarcina & Methanothrix \\
\hline Physiology & Generalist & Specialist \\
\hline Substrates & Acetate, hydrogen, methanol, methylamines & Acetate \\
\hline Specific growth rate $\left(\right.$ day $\left.^{-1}\right)$ & 0.3 & 0.1 \\
\hline Doubling time (days) & $0.5-2$ & $1-12$ \\
\hline Yield $(\mathrm{g} / \mathrm{mol} \mathrm{Ac})$ & 2.1 & 1.4 \\
\hline $\mathrm{Km}(\mathrm{mM})$ & 3.0 & 0.5 \\
\hline
\end{tabular}

Methanothrix became the dominant methanogens, and Geobacter the most abundant and metabolically most active bacteria (Shrestha et al. 2013); metatranscriptomics revealed that the Methanothrix species in the digester were highly expressing genes for the reduction of carbon dioxide to methane (Rotaru et al. 2014b). These observations were quite remarkable as Methanothrix is not able to grow with $\mathrm{H}_{2}+\mathrm{CO}_{2}$ and lacks the essential hydrogenases of typical hydrogenotrophic methanogens. In a coculture of Methanosarcina barkeri and Geobacter metallireducens, direct interspecies electron transfer was involved in ethanol conversion (Wang et al. 2016), while in a coculture of $M$. barkeri and Pelobacter carbinolicus interspecies hydrogen transfer played a role (Rotaru et al. 2014a). Unlike Methanosaeta, Methanosarcina is able to grow with $\mathrm{H}_{2}+\mathrm{CO}_{2}$. Methanosarcina can perform a hydrogen-dependent relationship with other bacteria. When sulfate is present, Methanosarcina can transfer hydrogen formed in the conversion of methanol or acetate to a sulfatereducing Desulfovibrio (Phelps et al. 1985). Methanosarcina can act as hydrogen scavenger when a Desulfovibrio is grown on lactate without sulfate (Bryant et al. 1977). This shows that Desulfovibrio and Methanosarcina can both act as hydrogenproducing and hydrogen-consuming microorganisms, which makes it an interesting coculture for further genome-based studies (Plugge et al. 2010; Scholten et al. 2007).

In anaerobic environments, acetoclastic methanogens may compete with sulfatereducing bacteria for acetate. Research by Schönheit et al. (1982) showed that Desulfobacter postgatei outcompeted Methanosarcina barkeri for acetate. This was explained by differences in affinity for acetate; the $\mathrm{Km}$ values for acetate are 0.2 and $3.0 \mathrm{mM}$ for the sulfate reduce and the methanogen, respectively. However, Methanothrix is often the most abundant acetoclastic methanogen and as explained, Methanothrix has a higher affinity for acetate than Methanosarcina (Jetten et al. 1992). In addition, Desulfobacter is a typical marine sulfate reducer, while in freshwater environments, Desulfobacca acetoxidans is an important sulfate reducer specialized in degradation of acetate (Oude Elferink et al. 1999). The Km for acetate of this bacterium is $0.1-1 \mathrm{mM}$, which is just slightly lower than that of Methanothrix ( $\mathrm{Km}$ is 0.4-1.2 mM) (Oude Elferink et al. 1998; Stams et al. 2005). Also the threshold value for acetate consumption of $D$. acetoxidans is just slightly lower than that of Methanothrix. Thus, Methanothrix will be outcompeted by sulfate reducers, like D. acetoxidans. However, when a bioreactor with methanogenic sludge was fed with acetate and sulfate, it took a very long time before acetate was 
degraded by sulfate reducers, and it was calculated that it could take 200-500 days before methanogens and sulfate reducers became equally important in the conversion of acetate (Visser et al. 1993). This reflects the small differences in growth kinetic properties of the two types of microorganisms. An interesting feature in this respect is that acetoclastic sulfate reducers have a lower affinity for sulfate than hydrogenotrophic sulfate reducers (Laanbroek et al. 1984). This has important consequences. In environments where the sulfate concentration is not sufficient for complete degradation of organic matter, acetoclastic methanogens are not easily outcompeted and acetoclastic methanogenesis still prevails (Sousa et al. 2009).

\section{$4 \quad$ Pathway and Energetics}

Methanogenesis from acetate yields little energy. At standard conditions, the Gibbs free energy change of the conversion of acetate to $\mathrm{CO}_{2}+\mathrm{CH}_{4}$ is just $-31 \mathrm{~kJ} / \mathrm{mol}$, which is much less than the free energy needed to synthesize one ATP; the standard Gibbs free energy change for the phosphorylation of ADP to form ATP is $+45 \mathrm{~kJ} / \mathrm{mol}$ (Thauer et al. 1977). By contrast, the standard Gibbs free energy change of methane formation from $4 \mathrm{H}_{2}+\mathrm{CO}_{2}$ is $-136 \mathrm{~kJ}$ per mol. The pathway of acetotrophic methanogens was the subject of several excellent reviews (Ferry 2011, 2015; Schlegel and Müller 2013; Welte and Deppenmeier 2014). Available genome sequences are helpful to refine the insight of the pathways and energy conservation mechanisms. The initial step in the metabolism of acetate is the activation to acetylCoA (Fig. 1). Acetate activation in Methanothrix and Methanosarcina is different (Jetten et al. 1990). An acetate kinase/phospho acetyl transferase (AK/PAT) system is used by Methanosarcina species. This enzyme system has a high activity, but low affinity, which reflects the physiological features of Methanosarcina. The lowactivity but high-affinity AMP-dependent acetyl-CoA-synthetases (ACS) is used by Methanothrix. The AK/PAT system generates ADP, phosphate, and acetyl-CoA from ATP, CoA, and acetate, while the ACS converts ATP, CoA, and acetate to acetyl-CoA, AMP, and pyrophosphate (Jetten et al. 1990; Berger et al. 2012; Ferry 1992). The pyrophosphatase of Methanothrix is a soluble protein, which makes it unlikely that energy of pyrophosphate cleavage is conserved (Berger et al. 2012; Zhu et al. 2012). Remarkably, membrane-bound pyrophosphatase is present in Methanosarcina. Thus, the activation of acetate in Methanosarcina requires one ATP, while acetate activation in Methanothrix requires two ATP, as ATP + AMP is converted to ADP by adenylate kinase. Genes coding for enzymes in some acetoclastic methanogens are presented in Table 2. As acetoclastic methanogens grow with acetate as sole carbon and energy source, energy conservation mechanism should yield more than one and two ATP per molecule of acetate in Methanosarcina and Methanothrix, respectively.

Acetyl-CoA is converted to a methyl and carbonyl moiety by the action of a $\mathrm{CO}$ dehydrogenase/acetyl-CoA synthase (Fig. 1). At the enzyme, the carbonyl group is oxidized to $\mathrm{CO}_{2}$ and electrons are transferred to ferredoxin. The methyl group is transferred to a methanogenic cofactor (tetrahydromethanopterin) and subsequently transferred to coenzyme $\mathrm{M}$ by a membrane bound sodium translocating 


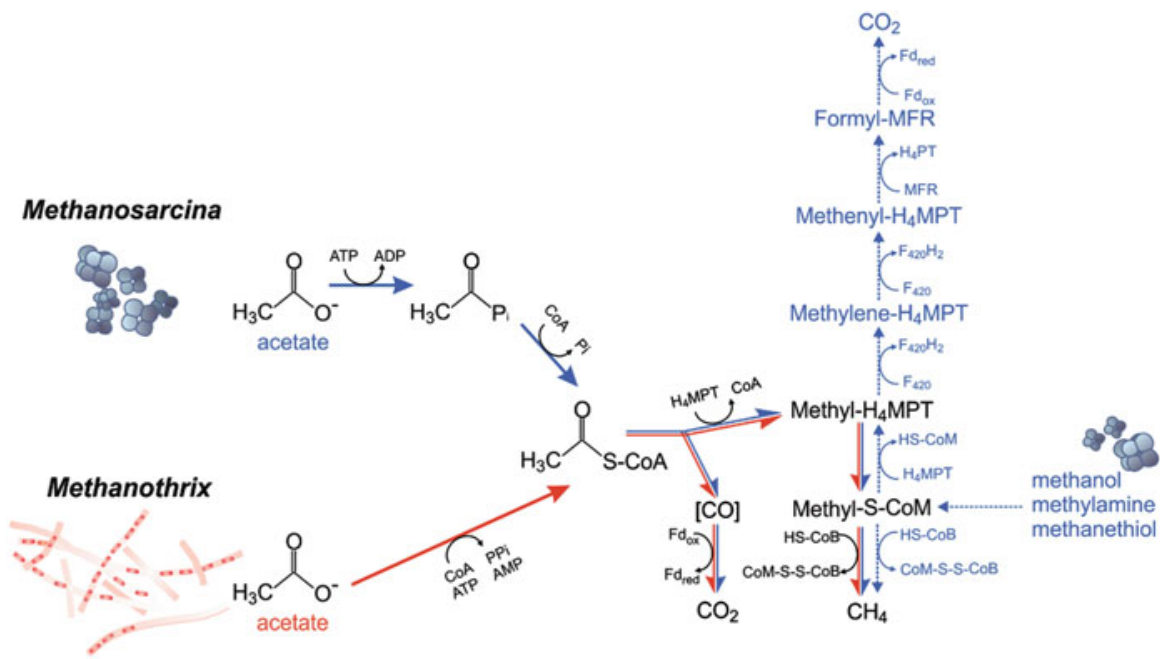

Fig. 1 Pathway of acetate conversion in Methanosarcina (blue arrows) and Methanothrix (red arrows). The pathway for the conversion of other methylated compounds by some species of Methanosarcina is also shown (text in blue and dashed arrows). Abbreviations: MFR, methanofuran; $\mathrm{H}_{4} \mathrm{MPT}$, tetrahydromethanopterin; HS-CoM, coenzyme M; HS-CoB, coenzyme B; $\mathrm{F}_{420} \mathrm{H}_{2}$, reduced form of the electron carrying coenzyme $\mathrm{F}_{420} ; \mathrm{Fd}$, ferredoxin; CoA, coenzyme A. (Adapted from Welte and Deppenmeier (2014))

methyltransferase. Reduction of the methyl group to methane with coenzyme B as electron donor leads to the formation of a heterodisulfide (CoM-S-S-CoB). In both methanogens, the heterodisulfide is cleaved (reduced) to coenzyme $M$ and coenzyme $B$ with reduced ferredoxin, a process that results in energy conservation (Welte and Deppenmeier 2011; Feist et al. 2006). Methanosarcina barkeri employs an energy conserving hydrogenase (Ech) complex and F420 nonreducing hydrogenase, while M. acetivorans uses an Rnf-like complex (Li et al. 2006; Ferry 2015; Schlegel and Müller 2013). The involvement of these membrane bound enzyme systems results in the formation of an electrochemical gradient (protons, sodium) to drive ATP synthesis (Wang et al. 2011). In the genomes of Methanothrix species, the genes for Ech or the Rnf-like complex are not present (Barber et al. 2011; Zhu et al. 2012; Welte and Deppenmeier 2011). Instead, a multi-gene cluster encoding for a reduced F420 dehydrogenase, which is not present in obligate hydrogenotrophic methanogens, but which is found in Methanothrix and in Methanosarcina, seems to play an important role in the formation of a proton gradient in Methanothrix when grown on acetate. As discussed by Welte and Deppenmeyer (2014), with some assumptions about the number of protons and sodium ions exported, sufficient energy could be conserved for net ATP synthesis. Generally, it is assumed that three protons or sodium ions drive the synthesis of one ATP, but the stoichiometry for methanogens was found to be four (Deppenmeier and Müller 2007). However, the way Methanothrix conserves energy needs further study. Modeling can help in prioritizing which possible explanations may be most likely. One powerful approach is called genome-scale metabolic modeling. 
Table 2 Genes (locus tags) involved in acetate activation in some representatives of acetoclastic methanogens. (Data obtained from the KEGG database)

\begin{tabular}{|c|c|c|c|c|}
\hline & \multicolumn{2}{|c|}{ Methanosarcina } & \multicolumn{2}{|l|}{ Methanothrix } \\
\hline & M. barkeri & $\begin{array}{l}\text { M. } \\
\text { thermophila }\end{array}$ & $\begin{array}{l}\text { M. } \\
\text { thermophila }\end{array}$ & M. concilii \\
\hline & $\begin{array}{l}\text { MS (DSM } \\
800)\end{array}$ & TM1 (1825) & $\begin{array}{l}\text { PT (DSM } \\
6194)\end{array}$ & $\begin{array}{l}\text { GP6 (DSM } \\
3671)\end{array}$ \\
\hline Acetate kinase & msbrm 2524 & mstht 1038 & & \\
\hline Phosphoacetyltransferase & msbrm 2525 & mstht 1037 & & \\
\hline ADP-dependent ACS & msbrm 2523 & mstht 1039 & & \\
\hline \multirow[t]{6}{*}{ AMP-dependent ACS } & & & mthe 0155 & mcon 0556 \\
\hline & & & mthe 1194 & mcon 0558 \\
\hline & & & mthe 1195 & mcon 0559 \\
\hline & & & mthe 1196 & mcon 0561 \\
\hline & & & mthe 1413 & mcon 0780 \\
\hline & & & & mcon 2868 \\
\hline \multirow[t]{4}{*}{ Pyrophosphatase } & msbrm 0400 & mstht 0033 & \multirow[t]{4}{*}{ mthe 0236} & \multirow[t]{4}{*}{ mcon 1906} \\
\hline & msbrm 0992 & mstht 0782 & & \\
\hline & \multirow[t]{2}{*}{ msbrm 2200} & mstht 1810 & & \\
\hline & & mstht 2185 & & \\
\hline \multirow[t]{2}{*}{ Adenylate kinase } & msbrm 2589 & mstht 1141 & mthe 0311 & mcon 1615 \\
\hline & msbrm 2695 & mstht 2391 & mthe 1504 & mcon 1964 \\
\hline
\end{tabular}

\section{$5 \quad$ Genome-Scale Metabolic Modelling}

Genome scale metabolic models are in essence a computable inventories of all metabolic reactions that the gene products - proteins, i.e., enzymes - of the genome can carry out (Henson 2015). Many bioinformatic tools and databases are available for such a metabolic reconstruction, and also for acetoclastic methanogens such genome-scale metabolic models are made (Feist et al. 2006; Benedict et al. 2012; Hanemaaijer 2016). Knowledge of the kinetic properties of redox enzymes involved in methanogenesis can be used to obtain insight in the physiology and the bioenergetics of acetoclastic methanogens, as discussed above; genome-scale models add a quantitative bookkeeping of all ATP-generating and ATP-consuming reactions in the metabolic network required for growth. Such models can run scenarios that are very difficult to perform experimentally, and in such a way combine molecular and physiological data to test the conditions at which specific hypotheses or stoichiometries are feasible.

For example, for Methanothrix concilii, Hanemaaijer (2016) reconstructed the metabolic network and investigated quantitatively which adjustments in the current stoichiometries of acetate activation and membrane pump stoichiometries (protons, sodium) would allow $M$. concilii to grow on acetate. For example, as a function of $\Delta \mathrm{pH}$ and specific metabolite levels, the maximum number of protons dissipated per 
ATP formed can be calculated, which is less than four (and likely more than three). Also if a membrane-bound, proton-pumping pyrophosphatase would be present (or engineered), the minimal number of protons will have to be two (1.8 in the model), again under some assumptions of unknown concentrations that determine the Gibbs free energy changes of the associated reactions. Despite that, in Methanothrix a typical energy-conserving membrane-bound pyrophosphatase is not present, but its ability to contribute to energy conservation is still possible. Welte and Deppenmeier (2014) proposed that pyrophosphate cleavage might be linked to other energydependent reactions in the anabolism by which at least partially the energy of pyrophosphate hydrolysis is conserved. In the models, it can be calculated which combination of changes in stoichiometries are feasible and which not, and based on this dedicated experimental validations can be suggested.

Genome-scale metabolic models are also often used in biotechnology for strain and process optimization (Branco dos Santos et al. 2013; Gottstein et al. 2016). For acetoclastic methanogens, who seem to live on the edge of thermodynamic feasibility, it is important to integrate thermodynamic constraints based on metabolite levels. Recently, such a genome-scale metabolic modeling approach was developed to understand how microbes, among which acetoclastic methanogens cope with substrate concentrations that prevail in natural environments (Shapiro et al. 2018). Such approaches should in the future be combined with additional cellular constraints based on either resource allocation (Basan 2018) or thermodynamics (Kümmel et al. 2006) to become powerful predictors of growth phenotypes.

\section{$6 \quad$ Concluding Remarks and Perspectives}

Two genera of acetoclastic methanogens, Methanosarcina and Methanothrix, have been described. There are remarkable differences between these two genera in terms of morphology and physiology. Acetoclastic methanogenesis is energetically not a very favorable process, but nevertheless, it is very important for complete degradation of organic matter. Research done to understand the metabolism and energyconservation mechanisms in acetoclastic methanogens showed differences in acetate activation and electron transfer mechanisms. Further genome-based transcriptome and proteome analyses, in combination with biochemical and modeling studies, will shed further light how these types of archaea cope with the energy constraints. Omics information will also help to understand better the interaction of acetoclastic methanogens with other microorganisms and with inorganic materials.

\section{$7 \quad$ Research Needs}

In methanogenic environments, acetate can be degraded by acetoclastic methanogens (Methanothrix and Methanosarcina) or by syntrophic associations of acetate-degrading bacteria and hydrogenotrophic methanogens. Further research is 
needed to define the exact environmental conditions stimulating direct and indirect methanogenesis from acetate.

In-depth genome-based analysis and genome-scale modeling offer the possibility to get further insight of the bioenergetic features of acetoclastic methanogens and to formulate hypotheses that can be tested. To completely resolve the bioenergetic properties of acetoclastic methanogens, physiological and enzymatic studies are needed.

Advances in the development of genetic systems in acetoclastic methanogens are still modest, with some successful genetic modification trials of Methanosarcina, but no attempts on Methanothrix. The ability to insert genes and create knock-outs of acetoclastic methanogens will aid the study of their physiology and bio-energetic features.

The observation that acetoclastic methanogens are involved in mediated electron transfer (MET), direct electron transfer (DET), and direct interspecies electron transfer (DIET) is intriguing. A better picture of the quantitative importance of electron transfer processes linked to acetoclastic methanogens can be obtained by studying pure culture and defined mixed cultures.

Acknowledgments This research was supported by the Soehngen Institute of Anaerobic Microbiology (SIAM) Gravitation grant (024.002.002) of the Netherlands Ministry of Education, Culture and Science and the Netherlands Organisation for Scientific Research (NWO), and by the ERC Advanced Grant Novel Anaerobes (no. 323009).

\section{References}

Albers SV, Meyer BH (2011) The archaeal cell envelope. Nat Rev Microbiol 9:414-426. https://doi. org/10.1038/nrmicro2576

Azman S, Khadem AF, Plugge CM, Stams AJM, Bec S, Zeeman G (2017) Effect of humic acid on anaerobic digestion of cellulose and xylan in completely stirred tank reactors: inhibitory effect, mitigation of the inhibition and the dynamics of the microbial communities. Appl Microbiol Biotechnol 101:889-901. https://doi.org/10.1007/s00253-016-8010-x

Barber RD, Zhang L, Harnack M, Olson MV, Kaul R, Ingram-Smith C, Smith KS (2011) Complete genome sequence of Methanosaeta concilii, a specialist in aceticlastic methanogenesis. J Bacteriol 193:3668-3669. https://doi.org/10.1128/JB.05031-11

Barker HA (1936) Studies upon the methane-producing bacteria. Arch Mikrobiol 7:420-438. https://doi.org/10.1007/BF00407414

Basan M (2018) Resource allocation and metabolism: the search for governing principles. Curr Opin Microbiol 45:77-83. https://doi.org/10.1016/j.mib.2018.02.008

Benedict MN, Gonnerman MC, Metcalf WW, Price ND (2012) Genome-scale metabolic reconstruction and hypothesis testing in the methanogenic archaeon Methanosarcina acetivorans c2a. J Bacteriol 194:855-865. https://doi.org/10.1128/JB.06040-11

Berger S, Welte C, Deppenmeier U (2012) Acetate activation in Methanosaeta thermophila: characterization of the key enzymes pyrophosphatase and acetyl-CoA synthetase. Archaea 2012:315153. https://doi.org/10.1155/2012/315153

Boone DR, Kamagata Y (1998) Rejection of the species Methanothrix soehngenii and the genus Methanothrix ${ }^{\mathrm{VP}}$ as nomina confusa, and transfer of Methanothrix thermophila ${ }^{\mathrm{VP}}$ to the genus Methanosaeta $^{\mathrm{VP}}$ as Methanosaeta thermophila comb. nov. Request for an Opinion. Int J Syst Bacteriol 48:1079-1080. https://doi.org/10.1099/ijs.0.2008/005355-0 
Branco dos Santos F, de Vos WM, Teusink B (2013) Towards metagenome-scale models for industrial applications - the case of Lactic Acid Bacteria. Curr Opin Biotechnol 24:200-206. https://doi.org/10.1016/j.copbio.2012.11.003

Bryant MP, Campbell LL, Reddy CA, Crabill MR (1977) Growth of Desulfovibrio in lactate or ethanol media low in sulfate in association with $\mathrm{H}_{2}$-utilizing methanogenic bacteria. Appl Environ Microbiol 33:1162-1169

De Vrieze J, Hennebel T, Boon N, Verstraete W (2012) Methanosarcina: the rediscovered methanogen for heavy duty biomethanation. Bioresour Technol 112:1-9. https://doi.org/ 10.1016/j.biortech.2012.02.079

Deppenmeier U, Müller V (2007) Life close to the thermodynamic limit: how methanogenic archaea conserve energy. In: Richter D, Tiedge H (eds) Bioenergetics. Springer, Berlin/ Heidelberg, pp 123-152. https://doi.org/10.1007/400_2006_026

Feist AM, Scholten JCM, Palsson B, Brockman FJ, Ideker T (2006) Modeling methanogenesis with a genome-scale metabolic reconstruction of Methanosarcina barkeri. Mol Syst Biol 2. https:// doi.org/10.1038/msb4100046

Ferry JG (1992) Biochemistry of methanogenesis. Crit Rev Biochem Mol Biol 27(6):473-503. https://doi.org/10.3109/10409239209082570

Ferry JG (2011) Fundamentals of methanogenic pathways that are key to the biomethanation of complex biomass. Curr Opin Biotechnol 22:351-357. https://doi.org/10.1016/j.copbio.2011. 04.011

Ferry JG (2015) Acetate metabolism in anaerobes from the domain archaea. Life 5:1454-1471. https://doi.org/10.3390/life5021454

Gottstein W, Olivier BG, Bruggeman FJ, Teusink B (2016) Constraint-based stoichiometric modelling from single organisms to microbial communities. J R Soc Interface 13:20160627. https:// doi.org/10.1098/rsif.2016.0627

Hanemaaijer MJ (2016) Exploring the potential of metabolic models for the study of microbial ecosystems. PhD dissertation, VU Amsterdam. ISBN: 978-94-6299-460-7

Henson MA (2015) Genome-scale modeling of microbial metabolism with temporal and spatial resolution. Biochem Soc Trans 43:1164-1171. https://doi.org/10.1042/BST20150146

Huser BA, Wuhrmann K, Zehnder AJB (1982) Methanothrix soehngenii gen. nov., a new acetotrophic nonhydrogen-oxidizing methane bacterium. Arch Microbiol 132:1-9. https://doi. org/10.1007/BF00690808

Jetten MSM, Stams AJM, Zehnder AJB (1990) Acetate threshold values and acetate activating enzymes in methanogenic bacteria. FEMS Microbiol Ecol 6:339-344. https://doi.org/10.1111/ j.1574-6968.1990.tb03958.x

Jetten MSM, Stams AJM, Zehnder AJB (1992) Methanogenesis from acetate: a comparison of the acetate metabolism in Methanothrix soehngenii and Methanosarcina spp. FEMS Microbiol Lett 88:181-197. https://doi.org/10.1111/j.1574-6968.1992.tb04987.x

Kamagata Y, Kawasaki H, Oyaizu H, Nakamura K, Mikami E, Endo G, Koga Y, Yamasato K (1992) Characterization of three thermophilic strains of Methanothrix ("Methanosaeta") thermophila sp. nov. and rejection of Methanothrix ("Methanosaeta") thermoacetophila. Int J Syst Bacteriol 42:463-468. https://doi.org/10.1099/00207713-42-3-463

Kreisl P, Kandler O (1986) Chemical structure of the cell wall polymer of Methanosarcina. Syst Appl Microbiol 7:293-299. https://doi.org/10.1016/S0723-2020(86)80022-4

Kümmel A, Panke S, Heinemann M (2006) Systematic assignment of thermodynamic constraints in metabolic network models. BMC Bioinforma 7:512. https://doi.org/10.1186/1471-2105-7-512

Laanbroek HJ, Geerligs HJ, Sijtsma VH (1984) Competition for sulfate and ethanol among Desulfobacter, Desulfobulbus, and Desulfovibrio species isolated from intertidal sediments. Appl Environ Microbiol 47:329-334

Li Q, Li L, Rejtar T, Lessner DJ, Karger BL et al (2006) Electron transport in the pathway of acetate conversion to methane in the marine archaeon Methanosarcina acetivorans. J Bacteriol 188:702-710. https://doi.org/10.1128/JB.188.2.702-710.2006 
Lovley DR (2017) Happy together: microbial communities that hook up to swap electrons. ISME J 11:327-336. https://doi.org/10.1038/ismej.2016.136

Martins G, Salvador AF, Pereira L, Alves MM (2018) Methane production and conductive materials: a critical review. Environ Sci Technol 52:10241-10253. https://doi.org/10.1021/acs. est.8b01913

Morita M, Malvankar NS, Franks AE, Summers ZM, Giloteaux L, Rotaru AE et al (2011) Potential for direct interspecies electron transfer in methanogenic wastewater digester aggregates. MBio 2:e0159-00111. https://doi.org/10.1128/mBio.00159-11

Nozhevnikova AN, Chudina VI (1985) Morphology of the thermophilic acetate bacterium Methanothrix thermoacetophila sp. nov. Microbiology 53:618-624

Oude Elferink SJWH, Luppens SBI, Marcelis CLM, Stams AJM (1998) Kinetics of acetate oxidation by two sulfate reducers isolated from anaerobic granular sludge. Appl Environ Microbiol 64:2301-2303

Oude Elferink SJWH, Akkermans-van Vliet WM, Bogte JJ, Stams AJM (1999) Desulfobacca acetoxidans gen. Nov. sp. nov., a novel acetate-degrading sulfate reducer isolated from sulfidogenic sludge. Int J Syst Bacteriol 49:345-350. https://doi.org/10.1099/00207713-49-2345

Patel GB (1984) Characterization and nutritional properties of Methanothrix concilii sp.nov., a mesophilic, aceticlastic methanogen. Can J Microbiol 30:1383-1396. https://doi.org/10.1139/ m84-221

Patel GB, Sprott GD (1990) Methanosaeta concilii gen. nov., sp. nov. ("Methanothrix concilii") and Methanosaeta thermoacetophila nom. rev., comb. nov. Int J Syst Bacteriol 40:79-82. https:// doi.org/10.1099/00207713-40-1-79

Phelps TJ, Conrad R, Zeikus JG (1985) Sulfate-dependent interspecies $\mathrm{H}_{2}$ transfer between Methanosarcina barkeri and Desulfovibrio vulgaris during coculture metabolism of acetate or methanol. Appl Environ Microbiol 50:589-594

Plugge CM, Scholten JC, Culley DE, Nie L, Brockman FJ, Zhang W (2010) Global transcriptomics analysis of the Desulfovibrio vulgaris change from syntrophic growth with Methanosarcina barkeri to sulfidogenic metabolism. Microbiology 156:2746-2756. https://doi.org/10.1099/ mic. $0.038539-0$

Rotaru AE, Shrestha PM, Liu F, Markovaite B, Chen S, Nevin KP, Lovley DR (2014a) Direct interspecies electron transfer during syntrophic growth of Geobacter metallireducens and Methanosarcina barkeri on ethanol. Appl Environ Microbiol 80:4599-4605. https://doi.org/ 10.1128/AEM.00895-14

Rotaru AE, Shrestha PM, Liu FH, Shrestha M, Shrestha D et al (2014b) A new model for electron flow during anaerobic digestion: direct interspecies electron transfer to Methanosaeta for the reduction of carbon dioxide to methane. Energy Environ Sci 7:408-415. https://doi.org/ 10.1039/C3EE42189A

Schlegel K, Müller V (2013) Evolution of $\mathrm{Na}^{+}$and $\mathrm{H}^{+}$bioenergetics in methanogenic archaea. Biochem Soc Trans 41:421-426. https://doi.org/10.1042/BST20120294

Schnellen CGTP (1947) Onderzoekingen over de methaangisting. PhD dissertation, Delft

Schnürer A, Zellner G, Svensson BH (1999) Mesophilic syntrophic acetate oxidation during methane formation in biogas reactors. FEMS Microbiol Ecol 29:249-261. https://doi.org/ 10.1111/j.1574-6941.1999.tb00616.x

Scholten JC, Culley DE, Brockman FJ, Wu G, Zhang W (2007) Evolution of the syntrophic interaction between Desulfovibrio vulgaris and Methanosarcina barkeri: involvement of an ancient horizontal gene transfer. Biochem Biophys Res Commun 352:48-54. https://doi.org/ 10.1016/j.bbrc.2006.10.164

Schönheit P, Kristjansson JK, Thauer RK (1982) Kinetic mechanism for the ability of sulfate reducers to out-compete methanogens for acetate. Arch Microbiol 132:285-288. https://doi. org/10.1007/BF00407967 
Shapiro B, Hoehler TM, Jin Q (2018) Integrating genome-scale metabolic models into the prediction of microbial kinetics in natural environments. Geochim Cosmochim Acta 242:102-122. https://doi.org/10.1016/j.gca.2018.08.047

Shrestha PM, Rotaru AE, Aklujkar M, Liu F, Shrestha M, Summers ZM et al (2013) Syntrophic growth with direct interspecies electron transfer as the primary mechanism for energy exchange. Environ Microbiol Rep 5:904-910. https://doi.org/10.1111/1758-2229.12093

Silva SA, Salvador AF, Cavaleiro AJ, Pereira MA, Stams AJM, Alves MM, Sousa DZ (2016) Toxicity of long chain fatty acids towards acetate conversion by Methanosaeta concilii and Methanosarcina mazei. Microb Biotechnol 9:514-518. https://doi.org/10.1111/17517915.12365

Smith KS, Ingram-Smith C (2011) Methanosaeta, the forgotten methanogen? Trends Microbiol 15:150-155. https://doi.org/10.1016/j.tim.2007.02.002

Söhngen N (1906) The formation and disappearance of hydrogen and methane under the influence of organic life. PhD dissertation, Delft

Sousa DZ, Alves JI, Alves MM, Smidt H, Stams AJM (2009) Effect of sulfate on methanogenic communities that degrade unsaturated and saturated long-chain fatty acids (LCFA). Environ Microbiol 11:68-80. https://doi.org/10.1111/j.1462-2920.2008.01740.x

Stams AJM, Plugge CM (2009) Electron transfer in syntrophic communities of anaerobic bacteria and archaea. Nat Rev Microbiol 7:568-577. https://doi.org/10.1038/nrmicro2166

Stams AJM, Plugge CM, de Bok FAM, van Houten BHGW, Lens P, Dijkman H, Weijma J (2005) Metabolic interactions in methanogenic and sulfate-reducing bioreactors. Water Sci Technol 52:13-20. https://doi.org/10.2166/wst.2005.0493

Thauer RK, Jungermann K, Decker K (1977) Energy conservation in chemotrophic anaerobic bacteria. Bacteriol Rev 41:100-180

Tindall BJ (2008) Rejection of the genus name Methanothrix with the species Methanothrix soehngenii Huser et al. 1983 and transfer of Methanothrix thermophila Kamagata et al. 1992 to the genus Methanosaeta as Methanosaeta thermophila comb. nov. Opinion 75. Int J Syst Evol Microbiol 58:1753-1754. https://doi.org/10.1099/ijs.0.2008/005355-0

Tindall BJ (2014) The genus name Methanothrix Huser et al. 1983 and the species combination Methanothrix soehngenii Huser et al. 1983 do not contravene Rule 31a and are not to be considered as rejected names, the genus name Methanosaeta Patel and Sprott 1990 refers to the same taxon as Methanothrix soehngenii Huser et al. 1983 and the species combination Methanothrix thermophila Kamagata et al. 1992 is rejected: supplementary information to Opinion 75. Judicial Commission of the International Committee on Systematics of Prokaryotes. Int J Syst Evol Microbiol 64:3597-3598. https://doi.org/10.1099/ijs.0.069252-0

Touzel JP, Prensier G, Roustan JL, Thomas I, Dubourguier HC, Albagnac G (1988) Description of a new strain of Methanothrix soehngenii and rejection of Methanothrix concilii as a synonym of Methanothrix soehngenii. Int J Syst Bacteriol 38:30-36. https://doi.org/10.1099/00207713-38$1-30$

't Zandt MH, van den Bosch TJM, Rijkers R, van Kessel MAHJ, Jetten MSM, Welte CU (2018) Cocultivation of the strictly anaerobic methanogen Methanosarcina barkeri with aerobic methanotrophs in an oxygen-limited membrane bioreactor. Appl Microbiol Biotechnol 102(13):5685-5694. https://doi.org/10.1007/s00253-018-9038-x

Visser A, Beeksma I, van der Zee A, Stams AJM, Lettinga G (1993) Anaerobic degradation of volatile fatty acids at different sulfate concentrations. Appl Microbiol Biotechnol 40:549-556. https://doi.org/10.1007/BF00175747

Wang M, Tomb JF, Ferry JG (2011) Electron transport in acetate-grown Methanosarcina acetivorans. BMC Microbiol 11:165. https://doi.org/10.1186/1471-2180-11-165

Wang LY, Nevin KP, Woodard TL, Mu BZ, Lovley DR (2016) Expanding the diet for DIET: electron donors supporting direct interspecies electron transfer (DIET) in defined co-cultures. Front Microbiol 7:236. https://doi.org/10.3389/fmicb.2016.00236

Welte C, Deppenmeier U (2011) Membrane-bound electron transport in Methanosaeta thermophila. J Bacteriol 193:2868-2870. https://doi.org/10.1128/JB.00162-11 
Welte C, Deppenmeier U (2014) Bioenergetics and anaerobic respiratory chains of aceticlastic methanogens. Biochim Biophys Acta 1837:1130-1147. https://doi.org/10.1016/j.bbabio.2013. 12.002

Zhu J, Zheng H, Ai G, Zhang G, Liu D, Liu X, Dong X (2012) The genome characteristics and predicted function of methyl-group oxidation pathway in the obligate aceticlastic methanogens, Methanosaeta spp. PLoS One 7(5):e36756. https://doi.org/10.1371/journal.pone.0036756

Zinder SH, Koch M (1984) Non-aceticlastic methanogenesis from acetate: acetate oxidation by a thermophilic syntrophic coculture. Arch Microbiol 138:263-272. https://doi.org/10.1007/ BF00402133 